\title{
Theories behind a nursing intern's error in terms of clinical decision-making
}

Meng $\mathrm{Wu}^{*}$

Xinyang Normal University, Xinyang, Henan 464000, China

Received: 27 October 2019; Accepted: 23 November 2019; Published: 20 September 2020

Abstract: Clinical decision-making and judgment is an essential skill that should be acquired by nursing interns. However, many studies reveal that a large proportion of nursing interns have difficulty in meeting the basic expectation of clinical decision-making. This article begins with a brief review of some theories related to clinical decision-making. Then it takes a case, for example, to show how the wrong decision is made. Furthermore, it makes a general analysis on the case drawing on the concept of bounded rationality, dual-process model, and skills acquisition theory. This article ends with some reflections from the case, to improve the consciousness and skills in decision-making for nursing interns.

Keywords: nursing intern $\bullet$ decision-making $\bullet$ review $\bullet$ bounded rationality $\bullet$ dual process theory $\bullet$ skill acquisition theory

(c) Shanxi Medical Periodical Press.

\section{Introduction}

The nursing internship year is the first time that nursing students face the real clinical settings, applying their knowledge and techniques gained from classrooms and laboratories into clinical practice. ${ }^{1}$ This year usually happens in the fourth year of their university time, and they will spend the whole year in the hospital to experience real clinical settings. Before starting their internship year, nursing schools will organize necessary practices and examinations for nursing students, ensuring that they can handle the basic operations in clinical practice. During the internship period, the hospital will arrange an experienced and knowledgeable nurse for each intern to guide and supervise their performance. This year is regarded as an indispensable period for students to obtain their bachelor certificate and prepare themselves for formal employment. Cherry and Jacob (2007) claimed that the internship year helps nursing students develop their competencies such as clinical decisionmaking, collaboration, communication, and critical thinking. ${ }^{2}$ Among these abilities, clinical judgment is seen as a vital and crucial capability as students are obliged to use it when they face dilemmas, multifaceted issues, and uncertain situations. ${ }^{3}$

Care interventions performed by interns, including injections, venous transfusion, and even urethral catheterization (directly), as well as administer medicines and ward inspection (indirectly), all have a significant impact on patient outcomes. Once errors happen in any part of the decision-making process, potentially harmful patient outcomes could occur. Adah also noted that

How to cite this article: Wu M. Theories behind a nursing intern's error in terms of clinical decision-making. Front Nurs. 2020;3:209-216. 
the competencies of interns, such as clinical decisionmaking and prioritization, can not only improve interns' performance but also increase potential benefits for the patient outcome. ${ }^{4}$ Therefore, clinical decision-making and judgment is an essential skill that should be acquired by nursing interns.

However, many studies reveal that a large proportion of nursing interns have difficulty in meeting the basic expectation of clinical decision-making and judgment. Del argued that there was a crisis, in clinical decision-making, that most new RN graduates didn't equip themselves with the required capability of clinical decision-making, such as failing to accurately recognize patients' priority problems, after Performance Management Services, Inc. utilized the performance-based developed system to assess staffs from different hospitals from the 1990 s to $2005 .{ }^{5}$ In addition, Ibrahim and Aly investigated the 150 nursing interns in Egypt by using the clinical judgment evaluation sheet and the Lasater clinical judgment rubric to evaluate their clinical judgment knowledge and skills, and the results were similar to the findings from the Performance Management Services, Inc. Such studies disclose that it is an urgent necessity to improve nursing interns' ability of clinical decision-making and judgment.

\section{Methods}

Most of the resources in this essay are from Leganto. Besides, using the CINAHI database to check articles about the status of nursing students' clinical decisionmaking and judgment by inserting "nursing interns or nursing internship or intern students" and "clinical decision making or clinical decision-making skills or clinical judgment." Inserting "nursing interns or nursing internship or intern students," "clinical decision-making or clinical decision-making skills or clinical judgment" and "education" to select the educational methods of improving students' clinical decision-making.

\section{Theories related to clinical decision-making and judgment}

Clinical decision-making and judgment are complex processes, and thus different scholars illustrate them in various ways. Clinical judgment is about judging what is going on, while decision-making refers to what should be done. ${ }^{6}$ According to Lauri et al., decision-making is a complex process involving obtaining available data and the evaluation of that data to take valid actions to get the desired outcome. ${ }^{7}$ Johansen and O'Brien clarified decision-making at a cognitive level, pointing out that the decisions made in nursing practice are influenced by various attributes, like intuition and analysis, heuristics, knowledge and experience, clinical reasoning and critical thinking, education and practice. ${ }^{8}$ First, nurses will perceive situations, make decisions by using several attributes mentioned above, and then reflect the outcome of the decisions. The following section will discuss how related theories impact on decision-making and judgment.

One classically related theory is called "bounded rationality," which regards that in decision-making, using rational processes is limited by the information the individual has, the cognitive limitations of their minds, and the finite amount of time they have to make a decision. ${ }^{9}$ This creative concept allowed Simon to win the Nobel prize in 1978. This definition of boundary rationality which emphasizes that there are restrictions on individual cognition is contrary to the previous description of perfect rationality that individuals have unlimited cognitive capabilities and can make rational choices, depending on their available resources. ${ }^{10}$ The theory of boundary rationality has been widely acknowledged and applied in multiple areas, including management, business, economics, medicine, nursing, and even daily lives because it gives people a logical explanation about how an irrational choice is made, allowing them to admit their weakness and encouraging them to have a profound reflection on some unreasonable decisions rather than giving them an assumption that a decision can be made rationally as long as they fully use valid resources.

If boundary rationality probes into why the irrational decisions are made, the dual-process theory explains how unreasonable behavior happens. Based on the belief that human rationality is bounded, the occurrence of irrational behavior is inevitable. In the dual-process theory, two systems in our mind exist oppositely: system 1 is associated with spontaneous, fast, and automatic mental operations, while system 2 is more consciously monitored and deliberately controlled. ${ }^{11}$ According to Stanovich, when people make a decision, these two systems can override to one other. For example, in normal cases, a novice will apply system 2, thinking deliberately, to conduct a task to ensure good performance. However, when in a governor-like mode-with somebody else monitoring, it seems that system 2 transfers to system 1 , making the decisions in fast speed and with less thinking, and an error might occur because of such transition. ${ }^{12}$

Apart from analyzing the decision-making on human rationality level, Dreyfus and Dreyfus prompted a model including five progressive stages on how learners make decisions-the skill acquisition theory. This theory posits that there are five stages during a student's learning process: novice, advanced beginner competent, proficient, and expert. One of the differences between 
these five stages is a movement from relying on rules to depending on past concrete experience. ${ }^{13}$ The model of skill acquisition is based upon the study of chess players and airline pilots originally, and then was applied in many other professional fields, including nursing. According to Benner, novice nurses need to be told the explicit rules or objective attributes, such as weight, intake and output, temperature, and other measurable parameters to guide their performance. However, expert nurses with enormous experiences have an intuitive understanding of the situation without wasteful consideration of related regulations or solutions, and the outcome of their judgment tends to be accurate and convincing. Nevertheless, that does not mean that the experts never use analytical cognitive processes. Benner clarified that the expert nurse would utilize the analytical thinking tool or rules when confronted with unfamiliar situations as well, but the skill acquisition theory has never mentioned the situation what will happen when novices use their intuition. ${ }^{14}$

\section{A case}

This section will give a case happening on an intern in a Chinese hospital, trying to use the aforementioned theories to analyze how the wrong decision is made and give some enlightenment, trying to argue that a novice is not encouraged to engage system 1 and should follow the guides rather than intuition when they conduct any care interventions at the first time.

\subsection{The case}

It is a busy morning in the neurology unit, every ward is full of patients. MO is a mid-aged male in the general ward who needs an intramuscular injection on the gluteus. Intern nurse $\mathrm{M}$ is in her fourth year of an undergraduate program. She has just started her internship for about 2 weeks and suffers from sleep deprivation in the beginning of her internship. This day she is going to conduct the intramuscular injection for patient MO. In the nursing college, M practiced such a skill on the models for many times. However, this is the first time she had carried out this procedure on a patient in a clinical setting. Before entering the ward, M's clinical instructor $\mathrm{N}$ asked whether she is familiar with intramuscular injection and got a positive answer from $M$. Therefore, they went into the ward that contains eight patients. When M prepared the injection things, patient MO's two family members are all staring at her because they know $M$ is an intern but they didn't stop her instead of trying to trust her. Clinical teacher $\mathrm{N}$ pretends to look after another patient, but her eyes never left $\mathrm{M}$ for more than a minute. When $\mathrm{M}$ is going to sterilize the skin with alcohol,
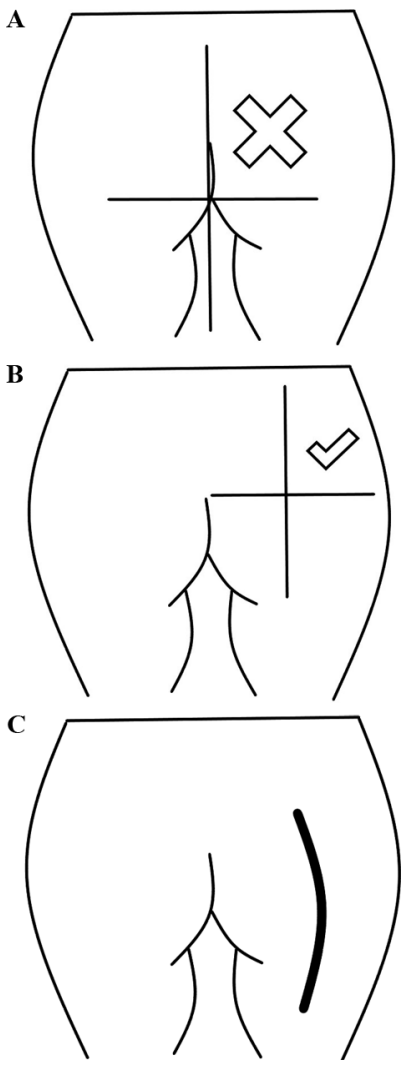

Figure 1. Different areas of gluteus.

her mind went blank suddenly, but she did not stop her movement instead of trying to remember where the correct injection area was. She knows it should be the right upper quadrant according to the crossed division line. However, she is a bit uncertain about where should the line be made. Relying on her impression, she chooses the second area (Figure 1-A) and sterilizes it. At this time, mentor $\mathrm{N}$ goes to $\mathrm{M}$ and questions the sterilized area. $\mathrm{M}$ hesitates for a second and points out the correct one (Figure 1-B). Then teacher $\mathrm{N}$ conducts the intramuscular injection for the patient successfully.

After going out of the ward, teacher $\mathrm{N}$ asks $\mathrm{M}$ : do you know the consequences if injected in the wrong area, and were you going to inject it if I didn't stop you. M said regretfully: yes, I know the consequence, it might cause nerve damage if injected in the wrong area. I don't know what was wrong with me at that time. In the end, teacher $\mathrm{N}$ requires $\mathrm{M}$ going back to review the whole process of intramuscular injection and related knowledge.

In this case, the process of the intern's decisionmaking is much simpler than many other clinical decisions. For experienced nurses, there is no need to think about how to locate the injection area when they carry out intramuscular injection for adult patients since they have practiced it for many times. Not only about this 
procedure, but it is also a common phenomenon in the nursing area that many decisions are made by "intuitive" approaches. ${ }^{15}$ Benner also indicated that intuition is an effective tool to ensure the desired patient outcomes by a nursing expert. However, for a new nurse in a clinical setting who carries out operations on real patients for the first time, many factors might confine her or his clinical decision-making.

\subsection{Analysis of the case}

The next section of this article will discuss the reason why the intern $\mathrm{M}$ makes an irrational decision drawing on the concept of bounded rationality, dual-process model and skills acquisition theory and then provide some reflection from this case.

\subsubsection{The "bounded rationality" concept}

Simon's bounded rationality indicates that individuals have limited cognition, and the external environment will affect their decision-making process. For the intern $M$ herself, her cognition is rather limited in the uncertain situation. Her knowledge about how to perform intramuscular injection is not solid, and she can not predict the outcome of her conduct on the spot, just as Simon points out there are three restrictions on cognition: incompleteness of information, difficulty in anticipating the consequences, and scarce knowledge of possible human behavior. In addition to the limited cognition, the external environment can be the factors as well, involving finite time, and the information the individual has. When $\mathrm{M}$ was in the nursing school, the test of the intramuscular injection was either in the form of paper examination or in the form of simulation test. In the paper examination, she had enough time to analyze where the correct injection area was. In the simulation test where the operation was conducted on the model, it was also not difficult for her to recognize the right area as that area had been practiced many times and thus was full of needle insertion marks. While in the real clinical practice, the time left for her to analyze was rather limited compared to analyzing time in the examination, and this operation was to be carried out on actual patients instead of a model. The change of the environment for what was wrong with me at that time. In the end, teacher $\mathrm{N}$ requires $\mathrm{M}$ going back to review the whole process of intramuscular injection and related knowledge.

In this case, the process of the intern's decisionmaking is much simpler than many other clinical decisions. For experienced nurses, there is no need to think about how to locate the injection area when they carry out intramuscular injection for adult patients since they have practiced it for many times. Not only about this procedure, but it is also a common phenomenon in the nursing area that many decisions are made by "intuitive" approaches. ${ }^{15}$ Benner also indicated that intuition is an effective tool to ensure the desired patient outcomes by a nursing expert. However, for a new nurse in a clinical setting who carries out operations on real patients for the first time, many factors might confine her or his clinical decision-making.

\subsection{Analysis of the case}

The next section of this article will discuss the reason why the intern $\mathrm{M}$ makes an irrational decision drawing on the concept of bounded rationality, dual-process model and skills acquisition theory and then provide some reflection from this case.

\subsubsection{The "bounded rationality" concept}

Simon's bounded rationality indicates that individuals have limited cognition, and the external environment will affect their decision-making process. For the intern $M$ herself, her cognition is rather limited in the uncertain situation. Her knowledge about how to perform intramuscular injection is not solid, and she can not predict the outcome of her conduct on the spot, just as Simon points out there are three restrictions on cognition: incompleteness of information, difficulty in anticipating the consequences, and scarce knowledge of possible human behavior. In addition to the limited cognition, the external environment can be the factors as well, involving finite time, and the information the individual has. When $\mathrm{M}$ was in the nursing school, the test of the intramuscular injection was either in the form of paper examination or in the form of simulation test. In the paper examination, she had enough time to analyze where the correct injection area was. In the simulation test where the operation was conducted on the model, it was also not difficult for her to recognize the right area as that area had been practiced many times and thus was full of needle insertion marks. While in the real clinical practice, the time left for her to analyze was rather limited compared to analyzing time in the examination, and this operation was to be carried out on actual patients instead of a model. The change of the environment for carrying out this skill, to some extent, results in $\mathrm{M}$ choosing to make an irrational and wrong decision.

\subsubsection{The dual-process model}

Alongside the notion of "bounded rationality," the dualprocess model can help to explain intern M's decision as well. The intern $M$ chose the system 1 , that is, intuitive approach, to judge the injection area since 
she tried to decide the correct area in a relatively fast speed and spontaneous way rather than deliberately considered it under the circumstance where she was not sure about the correct answer. Stress may be the major reason why $M$ chose system 1 . When $M$ carried out the procedure, she knew that the patient's families and her mentor were all overseeing her, which created invisible stress to her, as Stanovich argued that system 2 may turn to system 1 in a surveillance condition. Even though in normal cases, M knew the serious consequence if she injected in the wrong gluteus area. Due to the location of the sciatic nerve (Figure $1-C)$, it is highly likely to hurt sciatic nerve if choosing the Figure 1-A area and the consequence of such incorrect choice is irreparable, but in the stressful situation, she directly judged between the areas in Figures 1-A and $1-B$ instead of realizing that. Besides the stress from surveillance, intern M's stress also comes from being the new nurse in real work, lacking necessary skills and solid knowledge. All of these stresses, to a certain extent, lead $\mathrm{M}$ to analyze limitedly and make a relatively fast and spontaneous judgment without any previous experience. Compared with system 2, system 1 is a much simpler one. Johansen and O'Brien indicated that a stressful situation may result in oversimplified solutions, which can also interpret why intern $M$ chose the intuitive approach.

Ninety-five percent of our day-to-day decisions are intuitive. However, in clinical settings, from the author's view, when new novices conduct an intervention for the first time, they are not encouraged to make decisions with the system 1-fast and spontaneous but to break down decision-making into discrete explanatory components in an analytical and logical slower process (system 2). ${ }^{16}$ Although Standing suggested that the use of system 1 was not restricted to expert nurses as some novice nurses preferred to consciously or unconsciously use it when facing some critical incidents in clinical practice, but in most situations, especially in a general ward, nurses are allowed more time for analysis than in intensive care..$^{17}$ To receive a better patient outcome, the decision-making process of system 2 is recommended to new nurses who step into the clinical environment first. Not only for novice nurses, Dowie also noted that all nurses are supposed to increase the amount of analytic thought rather than rely on intuition when making a decision since that can ensure a complete examination of choices. ${ }^{18}$

\subsubsection{The skills acquisition theory}

According to the skills acquisition theory, novices usually follow the rules to guide their behavior, which seems limited and inflexible, but it is a relatively effective way to ensure patient safety. However, intern M's decisionmaking is contrary to this typical trait of a novice. When she faces the uncertain situation, no rule tells her what she should do with so many restricted factors. Even though in hindsight, the correct choice is to stop the procedure and turn to her clinical mentor. For intern $M$, it is hard for her to explain why she made such a decision on the premise of the fact that she knows the outcome of injecting in the wrong area in normal cases. Standing pointed out, in his book, that intuitive judgment is a subconscious process in which it is difficult to explain the reason for the decision. Particularly, the intuition is usually used by experienced professionals as, in nursing fields, intuition is usually gained from the reflection in and on practice and experiences.

The skills acquisition concept makes great sense in the clinical setting. Different levels of nurses are generally not encouraged to utilize other levels' tools to help them make decisions. For an expert nurse, intuition is regarded as an indispensable element in making decisions. When facing complex paramedic situations, just relying on the rules, knowledge, or past experiences is still hard for nurses to recognize which aspect of the problem is the most salient one. For the simple skills like in this case, it is possible for competent nurses to directly use their intuition to complete the intramuscular injection for patients, because, after a great deal of practice, there is no need for them to assist with crossing the line on patients' muscles to locate the correct injection area, instead, they can directly recognize it without any thinking. Nevertheless, for novice nurses, no matter how minor operations they are about to conduct, the rules and guides are not supposed to be ignored due to their lacking experiences and knowledge.

\section{Reflection}

In medicine, there is a term named "irreducible uncertainty" that will cause a failure in decision-making. ${ }^{19}$ The aforesaid concept also suggests that human's rationality is bounded. For intern nurses who step into the real working place for the first time, it is hard to expect zero error in decision-making. However, as nurses, it is the basic line for them to be accountable for patients, whether for a novice nurse or for an expert nurse. At this time, the supervision and guidance from the clinical instructor are extremely important, as Reason mentioned that the error management-creating system, which is available to tolerate the occurrence of errors, can be more effective than just insisting the individual be less fallible. ${ }^{20}$ Although it is hard to change the fact that nursing interns lack experience, the working environment (e.g. closed supervision and guidance) that they work in can be changed. 
After the occurrence of error in clinical settings, the comprehensive reflection should be followed. For clinical mentors, it is important for them to monitor, guide, and even appropriately blame the interns, even though Reason considered that blaming the individual has serious shortcomings and is ill-suited in patient care domain. However, to some extent, it is an effective method to raise the awareness of the accountability of nursing interns, allowing them to predict the consequence when they make the next choice. In addition, helping the interns to analyze the reasons behind such mistakes, giving related suggestions, and avoiding the recurrence of the same error could also be seen as the necessary measures for clinical mentors, as Reason suggested that the effective risk management depends crucially on establishing a reporting culture..$^{21}$

\section{Discussion}

In this case, the error made by the intern is mainly because of the lack of solid professional knowledge. However, the decision made by $\mathrm{M}$ under the uncertain circumstance is largely caused by lacking related clinical decision-making knowledge. Although many objective factors constrain M's rationality, the enhanced ability of clinical judgment can be improved to break through these constrictions.

Many reasons could contribute to irrational clinical decision-making caused by nursing interns. To begin with, as new nurses who step into clinical setting initially, their clinical experience is not enough. It was mentioned by Benner et al that massive daily decision-making in clinical settings depends on experiential knowledge..$^{22}$ Due to the insufficiency of such experiential knowledge, nursing interns might make errors when they conduct procedures. In addition, nursing interns could feel stressed when they make decisions and thus ill decisions could happen, because, in most cases, they are under the supervision of clinical mentors and face the distrust from patients. Last but not least, their ability to situation awareness is limited. The context and tasks are all both unfamiliar to them. Therefore, errors in clinical practice made by nursing interns could tend to happen easily.

Even though so many restrictions are imposed on interns' rational thinking, it is still important for them not to use their intuition to make decisions in clinical practice. Apart from the intuition, the heuristics is also not encouraged to be used by nursing interns. According to Redelmeier et al, the heuristics is an approach that draws one's experience to simplify a complex decision. ${ }^{23}$ It is a "rule of thumb" for many nursing professionals since it will save time and help nurses to achieve their desired outcome by using minimum effort, but the use of heuristics is on the premise of having abundant experience. It has been suggested by qualitative studies that the use of past experiences and heuristics to reason is more efficient. ${ }^{24}$ However, for interns who step into the real workplace for the first time, most of the decisions made by them are not complex in the beginning. There is no need to use the heuristics to achieve the desired goal. Therefore, it should be aware for nursing interns to make decisions by the system 2 process, analyzing the situation, predicting the consequence, and making a rational decision.

For novice interns, apart from the expectation for them to recognize the main problem of patients, it is considerably important for them not to counter the interests of patients, ensuring the optimal patient safety. Hence, they are expected to follow the given rules no matter how limited and inflexible they are in most cases, since they have no experience and concrete theory-to-practice knowledge. For clinical mentors, they also play a significant role to give them explicit explanation of rules and create the space for interns to reflect. It is equally crucial for them to have a clear understanding of their students' skill level and assign the corresponding task for them. Benner suggested that, in guiding novice nurses, the clinical mentors should be at least at a competent level since the advanced beginner can not sort out what is important in attending patients.

Moreover, the ability of clinical decision-making can be improved by education. Many studies try to improve nursing student clinical decision-making by utilizing different tools. A study conducted by Kaddoura (2016) found that the use of concept mapping enables to foster the growth of clinical judgment skills in nursing students. ${ }^{25}$ Besides, the simulation debriefing is also considered as a valid method to enhance students' clinical judgment by actively appraising student's cognitive, affective, and psychomotor performance. ${ }^{26}$ Not only should the nursing college try to improve the students' clinical decision-making and judgment, the hospital where the intern students work in also has the responsibility to organize some activities to facilitate intern's clinical decision-making level.

\section{Conclusions}

Nursing interns' clinical decision-making and judgment still have considerable room for improvement. The internship year is a transitional period for nursing students to transfer their academic theories into the real clinical workplace. During this period, they need time to adjust to and a suitable instructor to guide them, pointing out what is the salient aspect of one situation. If an 
error happens, the suitable blame is acceptable, but more significant is to encouraging intern students to reflect on the past irrational decision and the hospital also needs to provide a holistic system to prevent the error and try to organize activities to improve students' clinical decision-making ability.

As a new worker in real practice, many factors such as lacking experience, stress, and so on, to some extent, confine intern's rationality. However, in most cases, interns are not supposed to use their intuition or heuristic to make a decision. On the contrary, they

\section{References}

1. Ibrahim AF, Aly AA. Clinical judgment among nursing interns. Clin Nurs Stud. 2018;6:19.

2. Cherry B, Jacob SR. Contemporary Nursing Issues: Trends and Management. St. Louis: Mosby; 2007.

3. Bakr MM, Sherif NM, Eid NM, ELshal SE. Factors influencing decision making and its effect on intern students clinical performance. World Appl Programm. 2013;32:75-84.

4. Adah Chung. About Clinical Performance of Nursing Students; 2008. http://www.ehow.com/ about_6163234_clinical-performance-nursing-students.html. Accessed July 25, 2019.

5. Del Bueno D. A CRISIS in critical thinking. Nurs Educ Perspect. 2005;26:278-282.

6. Dowding D, Thompson C. Measuring the quality of judgement and decision-making in nursing. J Adv Nurs. 2003;44:49-57.

7. Lauri S, Salantera S, Chalmers K. et al. An exploratory study of clinical decision-making in five countries. J Nurs Scholarsh. 2001;33:83-90.

8. Johansen ML, O'Brien JL. Decision making in nursing practice: a concept analysis. Nurs Forum. 2016;51:40-48.

9. Simon HA. A behavioral model of rational choice. Q J Econ.1955;69:99-118.

10. Cristofaro M. Herbert Simon's bounded rationality. J Manage Hist. 2017;23:170-190.

11. Kahneman D. A perspective on judgment and choice: mapping bounded rationality. Am Psychol. 2003;58:697-720.

12. Stanovich KE. The Robot's Rebellion: Finding Meaning in the Age of Darwin. Chicago: The University of Chicago Press; 2004.

13. Dreyfus HL, Dreyfus SE. Five steps from novice to expert. In: Mind Over Machine. New York, NY: Free Press; 1986.

14. Benner P. From Novice to Expert: Excellence and Power in Clinical Nursing Practice. Menlo Park, are expected to utilize the given rules and system-2 decision-making strategy to guide their performance to ensure patient safety.

\section{Ethical approval}

Ethical issues are not involved in this article.

\section{Conflicts of interest}

There is no conflict of interest.
CA: Addison-Wesley Publishing Company, Nursing Division; 1984

15. Thompson C, Yang H. Nurses' decisions, irreducible uncertainty and maximizing nurses' contribution to patient safety. Healthcare $Q$ Toronto Ont. 2009;12(Spec No):e178-e185.

16. Croskerry P. Clinical cognition and diagnostic error: applications of a dual process model of reasoning. Adv Health Sci Edu. 2009;14(S1):27-35.

17. Standing $M$, Standing M. Clinical Judgement and Decision Making in Nursing and Interprofessional Healthcare. Maidenhead, Berkshire, England: McGraw Hill/Open University Press; 2010.

18. Dowie J, Dowie J. Evidence based, cost effective and preference driven medical decision making is the pre-requisite. J Health Serv Res Policy. 1996;1:104-113.

19. Hammond K. Human Judgment and Social Policy: Irreducible Uncertainty, Inevitable Error, Unavoidable Injustice. New York, NY: Oxford University Press; 2000.

20. Reason J. Human error: models and management. BMJ. 2000;320:768-770.

21. Reason J. Managing the Risks of Organizational Accidents. Aldershot: Ashgate; 1997.

22. Benner PE, Tanner CA, Chesla CA. Expertise in Nursing Practice. New York: Springer Press; 2009.

23. Redelmeier DA, Rozin P, Kahneman D. Understanding patients' decisions: cognitive and emotional perspectives. J Am Med Assoc. 1993;270:72-76.

24. Simmons B, Lanuza D, Fonteyn M, Hicks F, Holm $\mathrm{K}$. Clinical reasoning in experienced nurses. West $\mathrm{J}$ Nurs Res. 2003;25:701-719.

25. Kaddoura M, Kaddoura M. Impact of concept mapping on the development of clinical judgment skills in nursing students. Teach Learn Nurs. 2016;11:101.

26. AL Sabei SD. Simulation debriefing for clinical judgment development: a concept analysis. Nurse Educ Today. 2016;18:42-45. 